\title{
Impairment of cysteine synthesis from methionine in rats exposed to surgical stress
}

\author{
BY JOSÉ VIÑNA ${ }^{1}$, ANGEL GIMENEZ $Z^{2}$, INMACULADA R. PUERTES ${ }^{3}$, \\ ESPERANZA GASCO ${ }^{1}$ AND JUAN R. VIÑNA ${ }^{3}$ \\ ${ }^{1}$ Departamento de Fisiología, Facultad de Medicina, Av. Blasco Ibañez 17, Valencia-46010, Spain \\ ${ }^{2}$ Servicio de Cirugia, Hospital de la Marina Alta, Denia, Spain \\ ${ }^{3}$ Departamento de Bioquímica y Biología Molecular, Facultad de Medicina y Farmacia, \\ Av. Blasco Ibañez 15, I7 Valencia-46010, Spain
}

(Received 12 February 1991 - Accepted 19 September 1991)

The activity of liver cystathionase (EC 4.4.1.1) was decreased after $3 \mathrm{~d}$ of stress induced by surgery. The rate of $\mathrm{L}$-cysteine synthesis from $\mathrm{L}$-methionine was significantly higher in isolated hepatocytes from controls than in hepatocytes from rats suffering from surgical stress. The half-life of $L-12(n)-$ ${ }^{3} \mathrm{H}$ )methionine was significantly higher in rats submitted to surgical stress than in controls. Plasma Lmethionine: L-cystine ratio was higher in stressed rats than in controls. L-cystine uptake was significantly increased in the surgically-stressed rats when compared with the controls. All these facts are consistent with the hypothesis that the observed inhibition of cystathionase is physiologically important and that $L$ cysteine might be considered as an essential amino acid in cases of surgical stress.

Cystathionase: Surgical stress: L-cysteine synthesis: L-methionine: Rat

The synthesis of L-cysteine from L-methionine via the cystathionine pathway (Cooper, 1983) is important because dietary L-methionine is converted to L-cysteine in the liver. Thus, under normal metabolic conditions, the carbon skeleton of L-cysteine is considered as non-essential (Rose \& Wixom, 1955; Jackson, 1983, 1989). However, the essentiality of L-cysteine depends on the activity of the cystathionase pathway, which in turn, depends on cystathionase (EC 4.4.1.1) enzyme activity. Sturman et al. (1970) reported the absence of cystathionase in fetal tissues and postulated that L-cysteine might be an essential amino acid for the premature infant.

Jurgens (1982) showed that solutions for total parenteral nutrition that promoted maximal nitrogen retention in patients suffering from severe surgical stress were similar to those tailored for the premature infant which has a low cystathionase activity (Sturman et al. 1970; Zlotkin et al. 1981). Based on these facts we studied the effect of surgical stress on cystathionase activity in rat liver. We have found that surgical stress promotes a decrease in cystathionase activity and this is reflected in a decrease in the rate of $\mathrm{L}_{\text {-cysteine }}$ synthesis from L-methionine. Surgical stress also promotes increases in the plasma levels of L-methionine and decreases in plasma levels of total L-cystine. The present findings open the question that L-cysteine might be an essential amino acid in surgical stress.

\section{MATERIAL AND METHODS Rats}

Adult male Wistar rats were used. The care and handling of the rats conformed to the Guiding Principles for Research Involving Animals and Humans (recommendations from the declaration of Helsinki). Rats were maintained on a $12 \mathrm{~h}$ light $-12 \mathrm{~h}$ dark cycle under 
controlled conditions of temperature and humidity. The rats were fed on a non-purified diet containing $(\mathrm{g} / \mathrm{kg})$ : carbohydrates 530 , lipids 360 , proteins 143 . The protein source was soya bean, dry skimmed cow's milk, maize gluten, ground hard winter wheat and chickenmeat dry powder.

\section{Surgical stress procedure}

Surgical stress was induced as described by Garcia et al. (1989). Briefly, rats were anaesthetized with Pentothal $(50 \mathrm{mg} / \mathrm{kg}$ body-weight in physiological saline $(9 \mathrm{~g}$ sodium chloride/1)). A femoral fracture was induced in one side and a Kirschner needle was introduced in the femur to stabilize the fracture. Rats were then housed individually in cages for $3 \mathrm{~d}$. After this period, the animals were used for experiments.

\section{Studies in vivo}

Half-life of $L-\left[2(n)-{ }^{3} \mathrm{H}-\right]$ methionine. Pentothal $(50 \mathrm{mg} / \mathrm{kg}$ body-weight) was administered 3-5 min before the start of the experiment. L-[2(n)- $\left.{ }^{3} \mathrm{H}-\right]$ methionine $(0.5 \mathrm{ml}$ containing $5 \mu \mathrm{Ci}$, with a specific radioactivity of $50 \mathrm{mCi} / \mathrm{mmol}$ ) was injected into the tail vein. The rats were kept warm on a heated stage maintained at $38^{\circ}$. Blood $(0.2 \mathrm{ml})$ was collected from the femoral artery that had previously been catheterized, in heparinized tubes at $1,2,3,4,5$, $6,7,20 \mathrm{~min}$ after the injection. Blood samples were added to $2 \mathrm{ml}$ perchloric acid $(60 \mathrm{~g} / 1)$ and mixtures centrifuged to remove protein. Radioactivity was determined in the supernatant fraction $(0 \cdot 2 \mathrm{ml})$; for details, see Viña \& Williamson (1981).

Amino acid uptake by liver. The amino acids taken up by the liver were estimated by assuming that the portal vein and hepatic artery represent 70 and $30 \%$ of the afferent hepatic blood flow respectively (Greenway \& Stark, 1971). Blood was collected in heparinized syringes from the hepatic vein, portal vein and the aorta. The percentage hepatic uptake was calculated from the equation (Rémésy et al. 1978):

$$
\frac{0.3(\text { aorta }- \text { hepatic vein })+0 \cdot 7 \text { (portal vein }- \text { hepatic vein })}{0 \cdot 3(\text { aorta })+0 \cdot 7(\text { portal vein })} \times 100
$$

Amino acid determination. Amino acids were measured as described previously (Viña $e t$ al. 1981). Cysteine concentration was measured as described by Gaitonde (1967).

Measurement of cystathionase activity. This was measured as described by Heinonen (1973). Briefly, liver was homogenized in ice-cold $30 \mathrm{~mm}$-potassium phosphate buffer, $\mathrm{pH}$ 6.9. Homogenates were centrifuged at $28000 \mathrm{~g}$ for $30 \mathrm{~min}$ and the supernatant fluid was assayed. The reaction mixture for the assay of cystathionase activity contained the following $(\mu \mathrm{mol})$ in a total volume of $0.5 \mathrm{ml}$ : Tris-hydrochloric acid buffer $(\mathrm{pH} 8.4) 50$, pyridoxal 5 -phosphate 0.125 , L-cystathionine $1,0.63,0.5,0.25$ or 0.12 , tissue extract in $0.1 \mathrm{ml} 30 \mathrm{~mm}$-potassium phosphate buffer, $\mathrm{pH} 6.9$. The incubation time was $15 \mathrm{~min}$ and under the conditions of standard assay the rate of formation of cysteine was linear with time. The reaction was stopped by cooling the tubes in an ice bath. Dithiothreitol $(5 \mu \mathrm{mol} /$ tube) was added to bring all cystine to the reduced form and the amount of cysteine was determined by the spectrophotometric method of Gaitonde (1967).

\section{Studies in vitro}

Preparation of liver cells. This was done by the method of Berry \& Friend (1969) as modified by Romero \& Viña (1983). Cells (15-20 mg wet weight $/ \mathrm{ml})$ were incubated for 30 and $60 \mathrm{~min}$ in Krebs-Henseleit bicarbonate buffer. 
Table 1. Body-weight and food intake in control and surgically-stressed rats $\dagger$

(Mean values and standard deviations for no. of observations shown in parentheses)

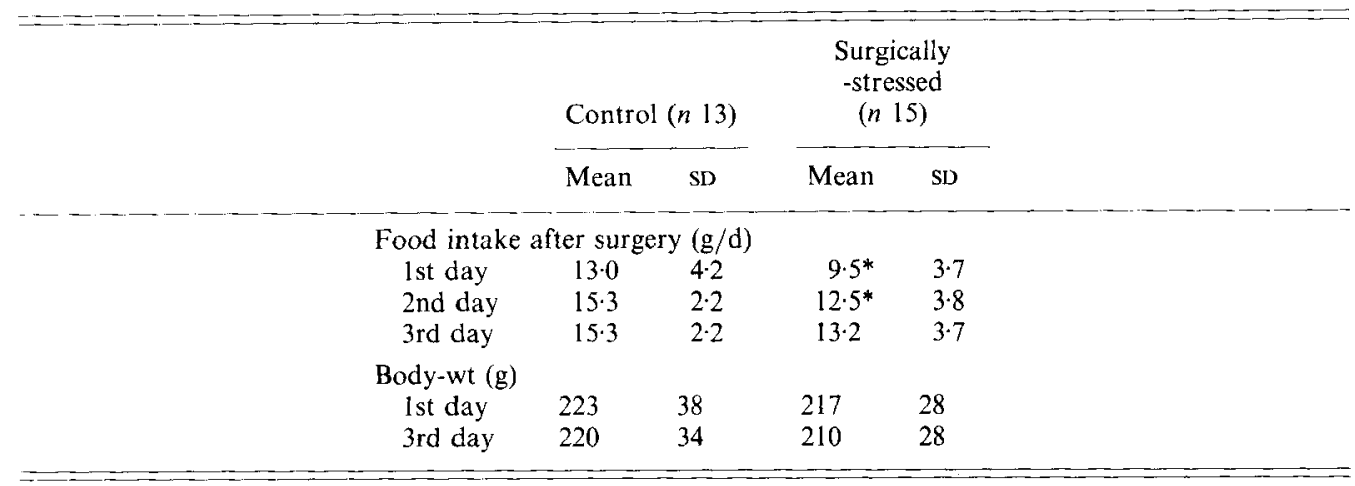

Mean values were significantly different from those for the controls: ${ }^{*} P<0.05$.

† For details of procedures, see pp. 421-422.

\section{Statistics}

The analyses were conducted by the least-significant-difference test, which consists of two steps. First, an analysis of variance was performed. The null hypothesis was accepted for all numbers of those sets in which $F$ was not significant at the level of $P<0.05$. Second, the sets of data in which $\mathrm{F}$ was significant were examined by the modified $t$ test at $P<0.05$.

\section{RESULTS}

Effect of surgical stress on food intake and body-weight of rats

Table 1 shows that on the first and second days after the surgical procedure the food intake in stressed rats was 73 and $80 \%$ of the control value respectively. By the third day it was not significantly different from that of the controls. The surgical procedure did not affect the body-weight of the rats (see Table 1).

\section{Rat liver cystathionase activity in stress induced by surgery}

The activity of liver cystathionase was decreased after $3 \mathrm{~d}$ of surgery (Table 2). However, this enzyme activity was not affected after $24 \mathrm{~h}$ of fasting or $4 \mathrm{~h}$ of stress induced by immobilization (results not shown). Enzyme activity was measured immediately after killing the animals.

\section{Effect of treatment of tissue samples on cystathionase activity}

Several studies have been performed in which cystathionase activity was measured in various tissues, including human biopsies. In most cases, samples of the tissue were maintained for several hours, or days, before measuring cystathionase activity. We addressed the question of whether this activity could be partly lost by this procedure and found that indeed this is the case. When rat livers were freeze-clamped and maintained in liquid $\mathrm{N}_{2}$ for $3 \mathrm{~d}, 55$ (SD 9$) \%(n 3)$ of the initial cystathionase activity was lost. Also, when liver biopsies were frozen and maintained at $-20^{\circ}$ for $24 \mathrm{~h}, 31$ (SD 4$) \%(n 3)$ of the initial cystathionase activity was lost. Thus, some caution must be exerted when interpreting data for cystathionase activity, especially if the enzyme is not assayed immediately after obtaining the liver samples. 
Table 2. Effect of surgical stress on cystathionase (EC 4.4.1.1) activity in rats $\dagger$

(Mean values and standard deviations for no. of observations shown in parentheses)

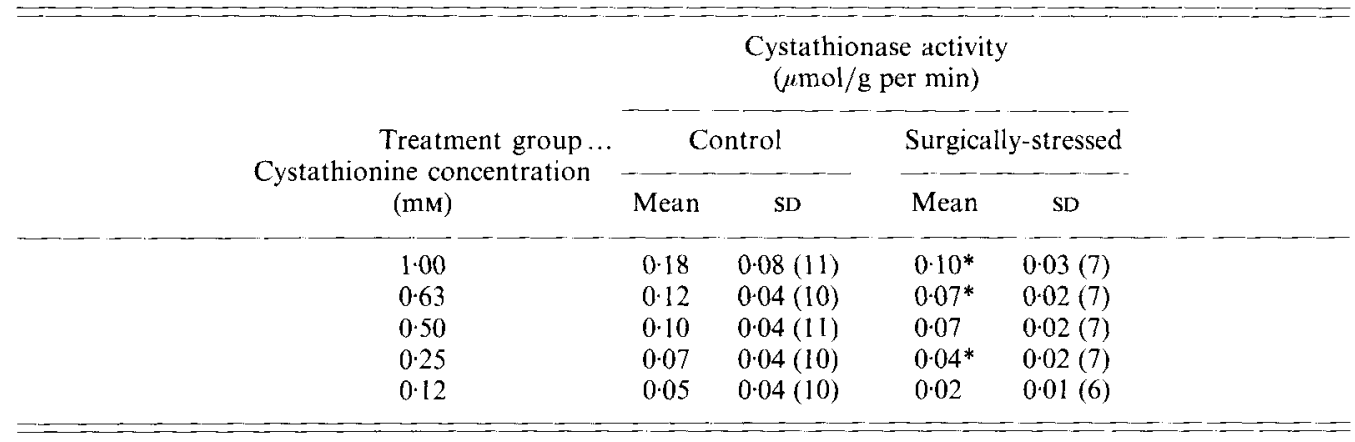

Mean values were significantly different from those of the controls: ${ }^{*} P<0.05$.

$\dagger$ For details of procedures, see pp. 421-422.

Effect of surgical stress on L-cysteine synthesis from L-methionine and $N$-acetylcysteine in isolated hepatocytes

We studied the rate of L-cysteine synthesis in isolated hepatocytes by measuring the Lcysteine concentration when no precursors were added and in the presence of two different mixtures of precursors. The first mixture had the following composition: L-glutamine $(5 \mathrm{~mm})$, glycine $(2 \mathrm{~mm})$, L-methionine $(0.5 \mathrm{~mm})$ and $\mathrm{L}$-serine $(1 \mathrm{~mm})$ and the second mixture had the following composition: L-glutamine ( $5 \mathrm{~mm}$ ), glycine ( $2 \mathrm{~mm})$ and $N$-acetylcysteine $(0.5 \mathrm{~mm})$.

The rate of $L$-cysteine synthesis is calculated from the L-cysteine concentration that is found when hepatocytes are incubated with precursors, minus the L-cysteine concentration found when the hepatocytes are incubated without precursors.

Table 3 shows that the rate of L-cysteine synthesis from L-methionine was significantly higher in isolated hepatocytes from controls than in hepatocytes from rats suffering from surgical stress. However, the rate of L-cysteine synthesis from $\mathrm{N}$-acetylcysteine, which does not depend on cystathionase activity, was significantly higher in rats submitted to surgical stress than in controls. The fact that this rate is higher after surgical stress than in controls might be explained by an increase in the transport of $\mathbf{L}$-cysteine by hepatocytes from rats with surgical stress. This increase in the cysteine uptake would compensate for the decreased rate of the cystathionase pathway in the stressed rats. The rate of glutathione synthesis from methionine or $\mathrm{N}$-acetylcysteine was not affected by surgical stress (results not shown).

\section{Half-life of $L-\left[2(n)-{ }^{3} H\right]$ methionine in control and in surgically-stressed rats}

In well-fed rats a major metabolic fate of methionine is its conversion to cysteine. Thus, if surgical stress promotes a metabolically significant decrease in cystathionase activity, one could expect to find the half-life of L-methionine significantly higher in rats submitted to surgical stress than in controls. Indeed, this is the case and we found that the half-life of $\mathrm{L}-\left[2(\mathrm{n})-{ }^{3} \mathrm{H}\right]$ methionine was 218 (SD 14) $\mathrm{s}(n 6)$ in control rats and 259 (SD 23) $\mathrm{s}(n)$ ) in rats submitted to surgical stress. The latter value was significantly higher $(P<0.05)$ than that found in control rats. A similar approach was used by Horowitz et al. (1981) who found that the transsulphuration pathway is impaired in cirrhosis. 
Table 3. Effect of surgical stress on L-cysteine synthesis from L-methionine and $N$ acetylcysteine in isolated hepatocytes from rats $\dagger$

(Mean values and standard deviations for no. of observations shown in parentheses)

\begin{tabular}{|c|c|c|c|c|c|c|c|c|c|}
\hline \multirow[b]{3}{*}{ Incubation } & \multirow{3}{*}{$\begin{array}{l}\text { Incubation } \\
\text { period } \\
\text { (min) }\end{array}$} & \multicolumn{4}{|c|}{ Control ( $n 3)$} & \multicolumn{4}{|c|}{ Surgically-stressed ( $n$ 5) } \\
\hline & & \multicolumn{2}{|c|}{$\begin{array}{c}\text { Cysteine } \\
\text { concentration } \\
(\mu \mathrm{mol} / \mathrm{g})\end{array}$} & \multicolumn{2}{|c|}{$\begin{array}{l}\text { Rate of cysteine } \\
\text { synthesis } t \\
(\mu \mathrm{mol} / \mathrm{g} \text { per } h)\end{array}$} & \multicolumn{2}{|c|}{$\begin{array}{c}\text { Cysteine } \\
\text { concentration } \\
(\mu \mathrm{mol} / \mathrm{g})\end{array}$} & \multicolumn{2}{|c|}{$\begin{array}{l}\text { Rate of cysteine } \\
\text { synthesis } \$ \\
(\mu \mathrm{mol} / \mathrm{g} \text { per } \mathrm{h})\end{array}$} \\
\hline & & Mean & so & Mean & SD & Mean & SD & Mean & SD \\
\hline & 0 & $1 \cdot 64$ & $0 \cdot 38$ & & & $2 \cdot 17$ & 0.44 & & \\
\hline & 60 & 1.65 & $0 \cdot 45$ & & & $2 \cdot 28$ & $0 \cdot 62$ & & \\
\hline AA-1 & 60 & 2.09 & 0.43 & 0.44 & 0.04 & $2 \cdot 48$ & 0.54 & $0 \cdot 20^{*}$ & $0 \cdot 14(5)$ \\
\hline $\mathrm{AA}-2$ & 60 & $9 \cdot 00$ & 0.47 & $7 \cdot 35$ & 0.64 & $18 \cdot 52$ & $4 \cdot 42$ & $16.24^{*}$ & $3.81(4)$ \\
\hline
\end{tabular}

AA-1, 5 mm-glutamine, 2 mm-glycine, 0.5 mm-methionine, 1 mm-serine; AA-2, 5 mm-glutamine, 2 mm-glycine, $0.5 \mathrm{~mm}-\mathrm{N}$-acetylcysteine.

Mean values were significantly different from those for the controls: ${ }^{*} P<0 \cdot 05$.

$\dagger$ For details of procedures, see pp. 42I-422.

* The rate of L-cysteine synthesis was calculated from the L-cysteine concentration found when hepatocytes were incubated with precursors, minus the L-cysteine concentration found when the hepatocytes were incubated without precursors.

Table 4. Arterial concentration of amino acids in rat with surgical stress

(Mean values and standard deviations for no. of observations shown in parentheses)

\begin{tabular}{|c|c|c|c|c|}
\hline \multirow[t]{2}{*}{ Treatment group... } & \multicolumn{2}{|c|}{$\begin{array}{l}\text { Control }(n 3) \\
(\mathrm{nmol} / \mathrm{ml})\end{array}$} & \multicolumn{2}{|c|}{$\begin{array}{c}\text { Surgically-stressed }(n \text { 3) } \\
(\mathrm{nmol} / \mathrm{ml})\end{array}$} \\
\hline & Mean & SD & Mean & SD \\
\hline Taurine & 201 & 37 & 331 & 152 \\
\hline L-threonine & I 64 & 55 & 159 & 7 \\
\hline L-serine & 114 & 10 & $225^{*}$ & 22 \\
\hline L-glutamic acid & 102 & 8 & 150 & 43 \\
\hline L-glutamine & 448 & 147 & 749 & 194 \\
\hline L-proline & 153 & 47 & 86 & 13 \\
\hline Glycine & 113 & 21 & $273^{*}$ & 33 \\
\hline L-alanine & 351 & 53 & $532 *$ & 28 \\
\hline L-valine & 126 & 10 & 126 & 21 \\
\hline L-cystine & 53 & 14 & $18^{*}$ & 1 \\
\hline L-methionine & 57 & 29 & 49 & 13 \\
\hline L-isoleucine & 90 & 36 & 51 & 2 \\
\hline L-leucine & 84 & 16 & $133^{*}$ & 13 \\
\hline L-tyrosine & 68 & 15 & 83 & 8 \\
\hline L-phenylalanine & 48 & 23 & 49 & 10 \\
\hline L-ornithine & 43 & 7 & 33 & 8 \\
\hline L-lysine & 275 & 34 & 314 & 36 \\
\hline L-histidine & 202 & 124 & 125 & 76 \\
\hline L-arginine & 135 & 24 & 148 & 28 \\
\hline
\end{tabular}

Mean values were significantly different from those for the controls: ${ }^{*} P<0.05$. 


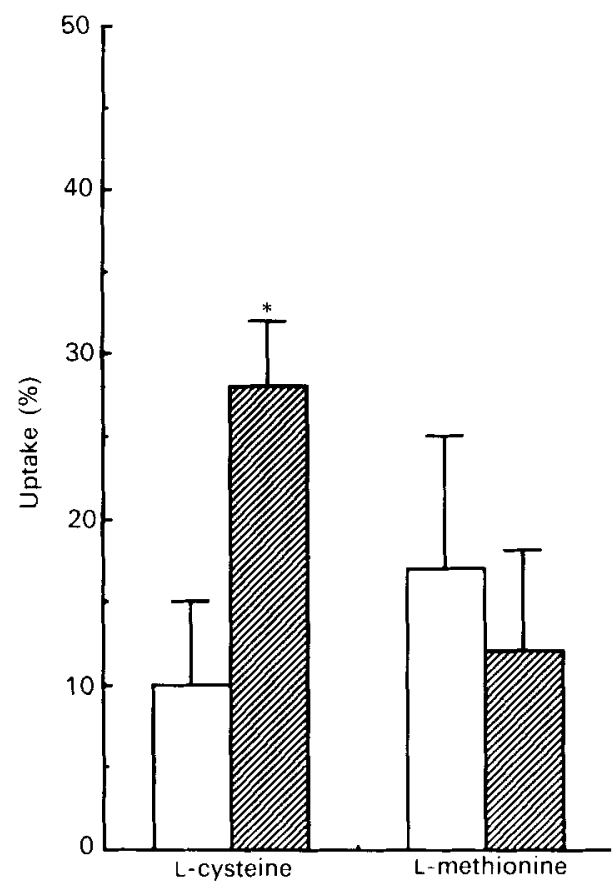

Fig. 1. L-methionine and L-cysteine uptake ( $\%$ ) by livers of control $(\square)$ and in surgically stressed rats ( $\nabla)$. Uptake values are expressed as a percentage of the total supply of each amino acid to the liver. For details of procedures, see pp. 421-422. Values are means and standard deviations represented by vertical bars for three observations for each group. Mean values were significantly different from those for the controls: ${ }^{*} P<0 \cdot 05$. For details of procedures, see pp. $421-422$.

Arterial concentration of amino acids in control rats and in surgically stressed rats

To test whether the decrease in cystathionase activity found had a significant effect on arterial plasma amino acid concentration, we measured the amino acid concentration in controls and in rats submitted to surgical stress. In these experiments plasma amino acids were measured using an amino acid analyser which gives the value of total L-cystine (Lcystine plus L-cysteine). The concentration of L-cystine was significantly lower in stressed rats than in controls (Table 4).

The L-methionine: $L$-cystine ratio in control rats and in stressed rats was 1.0 and 2.7 respectively. This result is in accordance with the decreased activity of liver cystathionase in stressed rats.

\section{Amino acid uptake by the liver}

The uptake of L-methionine and L-cysteine by the liver was measured in control and surgically-stressed rats. Uptake values are expressed as a percentage of the total supply of each amino acid to the liver. It was assumed that the percentage of blood flow to the liver from the aorta and portal vein does not change significantly with surgical stress.

The L-cysteine uptake was significantly increased by $200 \%$ in the surgically-stressed rats when compared with the control rats. the L-methionine uptake was only $15 \%$ lower in the stressed rats than in the control rats (Fig. 1). These results are consistent with the hypothesis that surgical stress induces a significant decrease in the cystathionase pathway. Thus, more $\mathrm{L}$-cysteine is taken up because there is a lower rate of $\mathrm{L}$-cysteine synthesis from L-methionine. 


\section{DISCUSSION}

Plasma amino acid concentration in animals under surgical stress

The levels of plasma amino acids in animals or patients under stress have been studied in the past. In all cases, using the values published (see Labrosse et al. 1967; Soley \& Alemany, 1980; Viña et al. 1981, 1983; Mans et al. 1982) the L-methionine: L-cystine (L-cystine + Lcysteine) ratio in controls was lower than 1 . This applies both to experimental animals and to humans (see Hamilton, 1973; Viña et al. 1987). However, when animals were exposed to stress they always had an L-methionine: L-cystine ratio higher than 1 (Stein \& Moore, 1954; Remesar et al. 1981; Milakofsky et al. 1986). Furthermore, in one study (Milakofsky et al. 1986) the controls had a catheter surgically fitted in the jugular vein (in itself a stressful condition) and in these animals the L-methionine: L-cystine ratio was $2 \cdot 2$. In another report (Remesar et al. 1981) the effect of thyroidectomy on plasma amino acid levels was studied. In this case the controls were sham-operated (and thus exposed to surgical stress) and their plasma L-methionine: L-cystine ratio was $2 \cdot 6$. Our controls were not exposed to any kind of surgical stress or anaesthetic agent. Thus they were not sham-operated as this procedure in itself induces surgical stress.

The fact that cystathionase is inhibited in animals under stress provides an explanation for the sulphur-amino acid pattern observed in the present study (Table 4) and in the reports quoted previously. When the cystathionase pathway is inhibited the conversion of L-methionine to L-cysteine is impaired and this results in a L-methionine: L-cystine ratio that is higher in animals under stress than in controls. This supports the theory that Lcysteine may be an essential amino acid in humans or animals under surgical stress.

\section{Possible essentiality of L-cysteine due to surgical stress}

L-cysteine is considered as a non-essential amino acid because it can be synthesized from L-methionine (Rose \& Wixom, 1955) by the transsulphuration pathway (Cooper, 1983). However, when cystathionase activity is decreased L-cysteine may become essential. This appears to be the case in the fetus and in the premature infant (Sturman et al. 1970; Zlotkin et al. 1981). We have recently found that L-cysteine synthesis from L-methionine is decreased in isolated hepatocytes from rat fetuses (Pallardó et al. 1991). The inhibition of cystathionase due to surgical stress reported here may have physiological importance because: (1) the half-life of $\mathrm{L}$-methionine is increased, (2) hepatic uptake of $\mathrm{L}$-cysteine from plasma is increased, (3) L-cysteine synthesis from L-methionine is decreased, (4) plasma Lcystine concentration is decreased. All these facts are consistent with the hypothesis that the observed inhibition of cystathionase is physiologically important and that L-cysteine might be considered as an essential amino acid in cases of surgical stress.

This raises the question of which can be an adequate source of L-cysteine, especially in patients exposed to surgical stress that are fed by total parenteral nutrition. L-cysteine itself is inadequate because it is unstable in aqueous solutions and because it may be toxic. We found that its toxicity is due to its rapid auto-oxidation (Vina et al. 1978, 1981) which generates free radicals (Saez et al. 1982). L-cysteine may be replaced by $N$-acetyl-L-cysteine (Neuhauser et al. 1986) or by glutathione which is stable in solution, non-toxic and can be a source of L-cysteine via a cystathionase-independent pathway (Hagen \& Jones, 1987; Viña et al. 1989).

The findings reported in the present paper may be of practical importance when trying to design a solution for total parenteral nutrition for patients suffering from surgical stress. 
This work was supported by grants of the Fondo de Investigaciones Sanitarias de la Seguridad Social FISS $89 / 0437$ to J.V., and FISS $90 / 0501$ to J.R.V. The authors acknowledge the skilful help of Miss Concha García and Mrs Juana Belloch.

\section{REFERENCES}

Berry, M. N. \& Friend, D. S. (1969). High yield preparation of isolated rat liver parenchymal cells: a biochemical and fine structural study. Journal of Cellular Biology 43, 506-520.

Cooper, A. J. L. (1983). Biochemistry of sulphur-containing amino acids. Annual Review of Biochemistry 52, $187-222$.

Gaitonde, M. K. (1967). A spectrophotometric method for the direct determination of cysteine in the presence of other naturally occurring amino acids. Biochemical Journal 104, 627-633.

Garcia, E., Schwartz, S., Farriol, M., Lopez, J. \& Andreu, A. L. (1989). Intracellular hepatic amino acids in postsurgical stress. Journal of Clinical Nutrition and Gastroenterology 4, 117-121.

Greenway, C. V. \& Stark, R. D. (1971). Hepatic vascular bed. Physiological Reviews 51, 23-65.

Hagen, T. M. \& Jones, D. P. (1987). Transepithelial transport of glutathione in vascularly perfused small intestine of the rat. American Journal of Physiology 252, G 606-G 613 .

Hamilton, P. B. (1973). Free amino acids in blood plasma of newborn infants and adults. Handbook of Biochemistry B-100. Boca Raton, FL, USA: CRC Press.

Heinonen, K. (1973). Studies on cystathionase activity in rat liver and brain during development. Effects of hormones and amino acids in vivo. Biochemical Journal 136, 1011-1015.

Horowitz, J. H., Rypins, E. B., Henderson, J. M., Heymsfield, S. B., Moffit, S. D., Bain, R. P., Chawla, R. K., Bleier, J. C. \& Rudman, D. (1981). Evidence for impairment of transsulfuration pathway in cirrhosis. Gastroenterology 81, 668-675.

Jackson, A. A. (1983). Amino acids; essential and non-essential? Lancet 1, 1034-1037.

Jackson, A. A. (1989). Optimizing amino acid and protein supply and utilization in the newborn. Proceedings of the Nutrition Society 48, 293-301.

Jurgens, P. (1982). Der postoperative Aminosaurenstoffwechsel. (Amino acid turnoves in the post-operative state). Infusionstherapie 9, 74-85.

Labrosse, E., Beech, J. A., McLaughlin, J. S., Mansberger, A. R., Keene, W. D. \& Cowley, R. A. (1967). Plasma amino acids in normal humans and patients with shock. Surgery, Gynecology and Obstetrics 55, 516-520.

Mans, A. M., Biebuyck, J. F., Shelly, K. \& Hawkins, R. A. (1982). Regional blood-brain barrier permeability to amino acids after portacaval anastomosis. Journal of Neurochemistry 38, 705-717.

Milakofsky, L., Miller, J. M. \& Vogel, W. H. (1986). Effects of acute ethanol administration on rat plasma amino acids and related compounds. Biochemical Pharmacology 35, 3885-3888.

Neuhauser, M., Grotz, K. A., Wandira, J. A., Bassler, K. H. \& Langer, K. (1986). Utilization of methionine and $N$-acetyl-cysteine during long-term parenteral nutrition in the growing rat. Journal of Clinical Investigation 35, 869-873.

Pallardó, F. V., Sastre, J., Asensi, M., Rodrigo, F. J., Estrela, J. M. \& Viña, J. (1991). Physiological changes in glutathione metabolism in foetal and newborn rat liver. Biochemical Journal 275, 891-893.

Remesar, X., Arola, L., Palou, A., Herrera, E. \& Alemany, M. (1981). Plasma amino acids in hypothyroid and hyperthyroid rats. Hormone and Metabolic Research 13, 38-41.

Rémésy, C., Demigne, C. \& Autreri, J. (1978). Inter-organ relationships between glucose, lactate and amino acids in rats fed on high-carbohydrate or high-protein diets. Biochemical Journal 170, 321-329.

Romero, F. J. \& Viña, J. (1983). A simple procedure to prepare isolated hepatocytes. Biochemical Education 11, $135-136$.

Rose, W. C. \& Wixom, R. L. (1955). The amino acid requirement of man. XIII The sparing effect of cystine on the methionine requirement. Journal of Biological Chemistry 216, 763-773.

Saez, G., Thornalley, P. J., Hill, H. A. O., Hems, R. \& Bannister, J. V. (1982). The production of free radicals during the autoxidation of cysteine and their effect on isolated rat hepatocytes. Biochimica et Biophysica Acta $719,24-31$.

Soley, M. \& Alemany, M. (1980). Amino acid concentrations in the plasma, serum and whole blood of the rat: Blood amino acid compartmentation. ICRS Medical Science 8, 159-160.

Stein, W. H. \& Moore, S. (1954). The free amino acids of human blood plasma. Journal of Biological Chemistry $19,915-926$.

Sturman, J. A., Gaull, G. \& Raiha, N. C. R. (1970). Absence of cystathionase in human fetal liver: Is cystine essential? Science $169,74-75$.

Viña, J., Hems, R. \& Krebs, H. A. (1978). Maintenance of glutathione content of isolated hepatocytes. Biochemical Journal 170, 627-630.

Viña, J., Perez, C., Furukawa, T., Palacin, M. \& Viña, J. R. (1989). Effect of oral glutathione on hepatic glutathione levels. British Journal of Nutrition 62, 683-691.

Viña, J., Puertes, I. R., Estrela, J. M., Viña, J. R. \& Galbis, J. L. (1981). Involvement of gamma-glutamyl transferase in amino acid uptake by the lactating mammary gland of the rat. Biochemical Journal 194, 99-102. 
Viña, J., Puertes, J. R., Montoro, J. B. \& Viña, J. R. (1983). Effect of specific inhibition of gamma-glutamyl transpeptidase on amino acid uptake by mammary gland of the lactating rat. FEBS Letters 159, 119-122.

Viña, J. R., Puertes, I. R., Rodriguez, A., Sáez, G. T. \& Viña, J. (1987). Effect of physiological starvation on amino acid metabolism by lactating mammary gland. Studies in women and rats. Journal of Nutrition 117 , $533-538$.

Viña, J. R. \& Williamson, D. H. (1981). Effects of lactation on L-leucine metabolism in the rat. Biochemical Journal 194, 941-947.

Zlotkin, S. H., Bryan, M. H. \& Anderson, G. H. (1981). Cysteine supplementation to cysteine-free intravenous feeding regimens in newborn infants. American Journal of Clinical Nutrition 34, 914-923. 